Revista Universo Contábil, ISSN 1809-3337

Blumenau, v. 14, n. 3, p. 112-134, jul./set., 2018

doi:10.4270/ruc.2018322

Disponível em www.furb.br/universocontabil

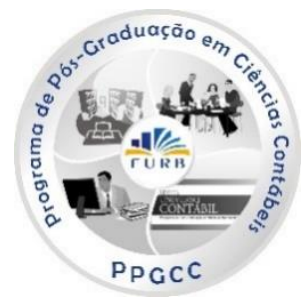

\title{
AS LÓGICAS INSTITUCIONAIS INCORPORADAS AO BALANCED SCORECARD (BSC): UM MODELO PARA ESTUDAR A ADAPTAÇÃO DO BSC ${ }^{1}$
}

\section{THE INSTITUTIONAL LOGICS EMBEDDED IN THE BALANCED SCORECARD (BSC): A MODEL TO STUDY BSC ADAPTATION}

\section{LAS LÓGICAS INSTITUCIONALES INCORPORADAS AL BALANCED SCORECARD (BSC): UN MODELO PARA ESTUDIAR LA ADAPTACIÓN DEL BSC}

\author{
Cláudio de Araújo Wanderley \\ $\mathrm{PhD}$ em Management pela Accounting pela University of Sheffiel \\ Professor do PPG em Ciências Contábeis da Universidade Federal de Pernambuco \\ Endereço: Av. dos Funcionários, s/n - 1aadar, sala E-6.1 \\ CEP: 50740-580 - Recife, PE - Brasil \\ E-mail: claudio.wanderley@ufpe.br \\ Telefone: (81) 21268911

\begin{abstract}
Gustavo Henrique Costa Souza
Mestre em Ciências Contábeis pela Universidade Federal de Pernambuco Doutorando em Ciências Contábeis pela Universidade Federal de Pernambuco Endereço: Av. dos Funcionários, s/n - 1 andar, sala E-6.1 CEP: 50740-580 - Recife, PE - Brasil gustavo.csouza@ufpe.br Telefone (81) 3031-6039
\end{abstract}

\section{RESUMO}

Este artigo examina a adaptação das práticas gerenciais, em nível intraorganizacional, com foco no Balanced Scorecard. O objetivo desse estudo é propor um modelo conceitual para o estudo da adaptação do BSC em nível intraorganizacional com base na literatura da lógica institucional e no modelo proposto por Ansari et al. (2010) - de que os padrões específicos de adaptação de práticas dependerão do ajuste entre a prática em difusão e a organização adotante. Neste artigo, sugere-se que a adaptação de práticas de contabilidade gerencial numa organização pode ser determinada pelo ajuste entre a lógica institucional dominante incorporada na empresa e a lógica institucional embutida na prática em difusão. Com base nesta proposição, foi desenvolvido um modelo conceitual para estudar a adaptação do BSC em nível intraorganizacional. Como resultado, oferece-se este modelo conceitual como uma forma analítica de usar o conceito de lógica institucional para explicar o processo de adaptação do BSC em uma organização.

\footnotetext{
${ }^{1}$ Artigo recebido em 18/04/2018. Revisado por pares em 27/11/2018. Reformulado em 06/12/2018. Recomendado para publicação em 07/03/2019 por Franciele Beck. Publicado em 30/03/2019. Organização responsável pelo periódico: FURB.
} 
Palavras-chave: Difusão de Contabilidade Gerencial; Mudança; Adaptação; Balanced Scorecard; Lógica Institucional.

\section{ABSTRACT}

This paper examines the adaptation of management practices at the intra-organizational level by focusing on the Balanced Scorecard. The aim of this study is to propose a theoretical framework to study the adaptation process of the BSC at the intra-organizational level by drawing on the existing institutional logics literature on practice variation and on the Ansari et al. (2010) view that the specific patterns of practice adaptation will depend on the fit between the diffusing practice and the adopting organization. We propose that management accounting practice adaptation in an organization is determined by the fit between the dominant institutional logics embedded in the firm and the institutional logics embedded in the diffusing practice. Based on this proposition, we developed a theoretical model to study the BSC adaption at the intra-organizational level. As a result, we offer our theoretical framing as an analytically useful way to use the concept of institutional logics to explain the process of adaptation of the BSC in an organization.

Keywords: Management Accounting Diffusion; Variation; Adaptation; Balanced Scorecard; Institutional Logics.

\section{RESUMEN}

Este estudio examina la adaptación de las prácticas de gestión a nivel intraorganizacional centrándose en el Balanced Scorecard. Nuestro objetivo es ampliar la literatura de lógicas institucionales existentes sobre la variación de la práctica recurriendo a Ansari et al. (2010), que consideran que los padrones específicos de adaptación de la práctica dependerán del ajuste entre la práctica de difusión y la organización de adopción. Proponemos que la adaptación de la práctica de contabilidad de gestión en una organización es determinada por el ajuste entre las lógicas institucionales dominantes integradas en la empresa y las lógicas institucionales integradas en la práctica de difusión. Con base en esta proposición, desarrollamos un modelo teórico para estudiar la adaptación del BSC a nivel intra-organizacional. Como resultado, ofrecemos nuestro encuadre teórico como una forma analítica que posibilita usar el concepto de lógica institucional para explicar el proceso de adaptación del BSC en una organización.

Palabras-clave: Difusión de Contabilidad Gerencial; Variación; Adaptación; Balanced Scorecard; Lógica Institucional.

\section{INTRODUÇÃO}

A literatura sobre a difusão das práticas entre as organizações é caracterizada por dois conjuntos de explicações concernentes aos processos de adoção. O primeiro tem suas origens na literatura econômica e se baseia no modelo do ator racional. Essa abordagem concebe adotantes como atores racionais que fazem escolhas eficientes (FISS; KENNEDY; DAVIS, 2012; KENNEDY; FISS, 2009; ROGERS, 1995). Como resultado, tem um apelo intuitivo imediato, uma vez que se centra nos benefícios econômicos presumidos que resultam da adoção de uma prática. O segundo conjunto de explicações é baseado em modelos sociológicos que tendem a adotar mais argumentos reputacionais que estão relacionados às crescentes pressões por conformidade social. Entre os modelos sociológicos, as "perspectivas de moda e mania" (ABRAHAMSON, 1991, 1996) e a perspectiva" institucional" são as abordagens mais populares (STURDY, 2004). A literatura de moda e mania visa explicar os processos de difusão baseando-se no pressuposto de que a adoção de práticas é determinada por imitação e não por escolha racional. 
A visão institucional postula que organizações que partilham do mesmo ambiente adotarão práticas semelhantes, ou seja, o conceito de isomorfismo. A visão institucional tem dois pressupostos principais. Em primeiro lugar, as organizações se adaptam não só a pressões técnicas, mas também às expectativas da sociedade (BOXENBAUM; JONSSON, 2008). Em segundo lugar, quando o processo de adaptação de novas práticas ocorre em função de pressões institucionais que são contrárias à eficiência interna necessária, as organizações afirmam usarem as práticas, mas na realidade não usam no dia-a-dia da empresa (decoupling) (BOXENBAUM; JONSSON, 2008).

Tanto as perspectivas racionais de difusão quanto às sociais costumam assumir uma perspectiva de nível populacional, enfatizando as condições intraorganizacionais (ANSARI; FISS; ZAJAC, 2010). Este enfoque intraorganizacional geralmente utiliza pressupostos simplificados sobre a homogeneidade das práticas de difusão através do tempo e espaço, tratando-as como essencialmente invariáveis ao invés de mutáveis. Pesquisadores de contabilidade gerencial também têm concentrado seus estudos sobre o nível do campo organizacional a fim de explicar e entender como agentes específicos adotam ideias particulares ou fenômenos, e por que fazem isso (ou não) (MACHADO; BJORNENAK, 2007). A literatura de contabilidade gerencial tem salientado a difusão como o processo pelo qual uma inovação é espalhada ou disseminada. Como consequência, geralmente não se investiga exaustivamente o que ocorre com as práticas introduzidas durante e após a adoção. Esta abordagem clássica da difusão baseia-se na prática invariável, em que adotantes passivos aceitam ou rejeitam a prática (BURKERT; LUEG, 2013).

Verifica-se, portanto, que há uma falha significativa nesta abordagem, uma vez que práticas de contabilidade gerencial não podem ser adotadas por empresas como soluções "de prateleira" (ANSARI et al., 2010). Assim, "Prática" pode ser definida como conjuntos de atividades materiais que estão fundamentalmente inter-relacionadas e que são moldadas por estruturas culturais mais amplas, como os sistemas de crenças e valores (LOUNSBURY; CRUMLEY, 2007). Lounsbury e Crumley (2007) apontam que parte do problema é que os estudos de difusão tratam práticas como objetos que são adotados ou não, levando essencialmente para a "caixa-preta" da prática. Quanto à adaptação, sugere-se aqui que é mais provável que ela seja uma regra do que uma exceção durante o processo de implementação, tendo em vista que poucas (se alguma) práticas de contabilidade gerencial saem do processo de difusão sem serem modificadas.

Gondo e Amis (2013) advogam por mais pesquisas sobre variação na adoção de práticas. Eles destacam que o entendimento sobre o que acontece dentro das organizações quando novas práticas são adotadas permanece ainda em um estágio inicial. Com este mesmo teor, Suddaby et al. (2010) lamentam que as pesquisas continuem focadas em "instituições" e prestem pouca atenção ao que ocorre nas organizações. Como consequência, a falta de explicação sobre a relação entre instituições e práticas organizacionais apresenta-se como uma "caixa preta" (SUDDABY, 2010).

Embora alguns estudiosos da contabilidade tenham dado atenção ao processo de adaptação e difusão de práticas de contabilidade gerencial utilizando-se, por exemplo, da Teoria Ator-Rede (TAR), o conceito de tradução (JUSTESEN; MOURITSEN, 2011; PRESTON; COOPER; COOMBS, 1992) e - da Teoria Institucional - conceitos como heterogeneidade organizacional, lógica institucional e variação de práticas (CRUZ; MAJOR; SCAPENS, 2009; EZZAMEL; ROBSON; STAPLETON, 2012; GUERREIRO; RODRIGUES; CRAIG, 2012; HYVÖNEN et al., 2009; WAGNER; MOLL; NEWELL, 2011), ainda falta, na literatura contábil, uma estrutura conceitual capaz de compreender os padrões de variação das práticas de contabilidade gerencial em todo o processo de difusão (ou seja, o processo de adaptação).

Utilizando-se de pesquisas sobre difusão e adaptação de práticas, com base na literatura da lógica institucional e do modelo teórico proposto por Ansari et al. (2010), pretende-se 
diminuir esta limitação e lançar mais luz sobre a pesquisa referente à adaptação de práticas de contabilidade gerencial. Argumenta-se aqui que, com o intuito de entender o padrão de adaptação de práticas de contabilidade gerencial durante o processo de difusão é necessário identificar e explicar os (des)ajustes entre a lógica institucional predominante em uma organização e a lógica institucional incorporada à prática de contabilidade gerencial adotada. Esta é uma característica distintiva deste estudo, já que poucos estudiosos tentaram explicar a variação analisando se as características da prática adotada são consistentes com as necessidades percebidas, objetivos e estrutura do adotante. Assim, a contribuição central desse trabalho é expandir o entendimento sobre o que ocorre com a prática contábil implementada durante e após a adoção da mesma. Isso é relevante, pois literatura na área de contabilidade gerencial tem enfatizado difusão apenas como um processo no qual uma inovação é transmitida e disseminada, sem discutir os mecanismos que afetam o processo de adaptação das práticas de contabilidade gerencial.

A pesquisa também tem um cunho prático bastante forte, pois pode contribuir para o entendimento por parte dos gestores e consultores organizacionais de como o processo de adaptação/customização de novas práticas gerenciais podem ter mais sucesso com menor dispêndio de recursos para assegurar a adequação da nova prática introduzida dentro de uma organização. Esse estudo evidencia a importância de se mapear e estudar as características técnicas, culturais e politicais de cada prática e organização de forma a identificar qual será a melhor forma de implementação da nova prática gerencial. Essa é uma nova perspectiva, pois a literatura sobre difusão vem focando apenas os aspectos técnicos do processo de adaptação, o que constitui um erro grave, pois muitas vezes os aspectos culturais e políticos são mais preponderantes para definir o sucesso do processo de difusão de uma nova prática no ambiente organizacional (ANSARI, et al. 2010).

O objetivo desse estudo é propor um modelo conceitual para o estudo da adaptação do BSC em nível intraorganizacional com base na literatura da lógica institucional e no modelo proposto por Ansari et al. (2010). Portanto, este trabalho examina a adaptação das práticas de contabilidade gerencial, em nível intraorganizacional, centrando-se no caso do Balanced Scorecard (BSC). Uma vasta gama de práticas de contabilidade gerencial foi introduzida desde a década de 1990, como o Balanced Scorecard (BSC), o Activity Based Costing (ABC) e o Target Costing. Entre essas práticas de contabilidade gerencial, o Balanced Scorecard pode ser considerado como um dos mais bem-sucedidos, pois o BSC parece ter durabilidade e se espalhou rapidamente pelo mundo, por exemplo, Rigby e Bilodeau (2011) relatam uma taxa de uso de $47 \%$ do BSC por empresas em todo o mundo. Qu et al. (2010) identificaram que uma das razões para o sucesso do BSC é o fato de que muitos usuários adotaram os pressupostos do BSC e adaptaram ele às suas próprias necessidades. A visão atual é que o BSC é um sistema genérico, que pode ser customizado para funcionar em harmonia com práticas locais. Portanto, pode-se argumentar que é a capacidade de adaptação e customização do Balanced Scorecard para com os elementos idiossincráticos das empresas é a principal razão para seu sucesso e popularidade (COOPER; EZZAMEL; QU, 2017). Dessa forma a artigo tem com questão problema norteadora do estudo: como ocorre o processo de adaptação do Balanced Scorecard em nível intraorganizacional?

O restante do trabalho está organizado em três seções principais. Primeiro, a exposição do arcabouço teórico adotado neste estudo. Em seguida, passa-se a apresentar uma visão geral e a discutir as principais características do BSC. Além disso, desenvolve-se e propõe-se um modelo para estudar a adaptação do BSC. A última seção traz as considerações finais. 


\section{REFERENCIAL TEÓRICO}

\subsection{Adaptação de práticas}

Neste trabalho, foi utilizada a mesma definição de adaptação apresentada por Ansari et al. (2010). Eles afirmam que a adaptação se refere ao processo pelo qual um adotante esforçase para criar uma melhor adequação entre a prática externa e as necessidades particulares do adotante, para aumentar sua "zona de aceitação" durante a implementação. O processo de adaptação pode envolver mudança na forma como uma prática é interpretada e estruturada no âmbito da organização ao longo do tempo (FISS; ZAJAC, 2006); ou pode envolver uma mudança na efetiva aplicação da prática em diferentes pontos do processo de difusão (KENNEDY; FISS, 2009).

Pesquisadores da Teoria Ator-Rede (TAR) usam o termo "tradução" em sentido similar à adaptação tanto para se referir a casos em que ideias e práticas são adaptadas aos contextos locais quanto para casos em que elas migram durante o processo de difusão (LATOUR, 1987). Portanto, a tradução é o que acontece com as práticas, quando elas são confrontadas com o mundo exterior. Descreve um processo por meio do qual uma prática é transformada em outra coisa. Esta visão com relação à adaptação de práticas implica que uma prática de contabilidade gerencial nunca é um pacote pronto e acabado a ser implementado, já que a prática é constantemente formatada e reformatada quando se difunde de um cenário a outro (JUSTESEN; MOURITSEN, 2011).

Ansari et al. (2010) sugerem que a adaptação de práticas envolve duas dimensões principais: similaridade e extensão. Em relação ao termo "similaridade", Ansari et al. (2010) utilizam o termo "fidelidade", ao invés do termo de "similaridade". No entanto, temos o mesmo entendimento de Fiss et al. (2012), que o termo "similaridade", representa melhor a definição dessa dimensão do processo de adaptação, uma vez que "similaridade" mede quão semelhante é uma prática adotada das suas versões anteriores. Como resultado, similaridade está relacionada a se uma prática implementada se assemelha ou afasta-se das características da versão anterior desta mesma prática à medida que se difunde em uma organização (FISS et al., 2012). Ansari et al. (2010) destacam que a noção de protótipo é muito útil para mapear as variações possíveis em uma prática em constante evolução ao longo do tempo. Os autores concluem que protótipos de práticas, portanto, podem ser usadas para avaliar a similaridade dos processos de adaptação em relação o protótipo original, bem como, em relação a versões posteriores.

A segunda dimensão, extensão, mede o grau de implementação da prática. Extensão em adaptação indica em que medida a prática introduzida apresenta esforços de longo alcance ou restritos com a finalidade de implementação (ANSARI et al., 2010). Como consequência, esta dimensão dá uma noção de escala de implementação. Ambas as dimensões são conceitualmente diferentes, de forma que a extensão avalia o grau das mudanças enquanto a similaridade avalia o tipo destas mudanças (FISS et al., 2012). Ansari et al. (2010, p. 73) explica que "práticas são altamente fiéis, mas não extensas, quando estão mais ligadas à sua versão anterior - sem, contudo, terem sido implementadas largamente. E práticas são extensas, mas com baixa fidelidade se forem largamente implementadas - mas não forem fieis à sua versão primária". Fiss et al. (2012) concluem que estas duas dimensões são adequadas para analisar a adaptação da prática, porque elas são capazes de capturar tanto a natureza de uma prática como a sua efetiva implementação.

\subsection{Modelo teórico de Ansari et al. (2010)}

Ansari et al. (2010) explicam a adaptação como uma resposta à falta de adequação entre as características da organização adotante e as características inerentes à prática. Os autores estabelecem que a principal razão pela qual uma organização adapta uma prática que está sendo 
implementada é que as características da prática não se adequam às características da organização adotante. "Ajuste" pode ser definido como a medida pela qual necessidades, demandas, metas, objetivos e/ou conceitos de um componente são consistentes com as necessidades, demandas, metas, objetivos e/ou estruturas de outro componente (NADLER; TUSHMAN, 1980). Como consequência, o modelo teórico de Ansari et al. (2010) procura explicar os padrões de adaptação de prática mediante a análise de como as características das práticas de difusão interagem com as características dos adaptadores.

A fim de conceituar ajuste, Ansari et al. (2010) utilizaram, com base em Oliver (1992), a categorização de fatores que influenciam as práticas organizacionais. Ansari et al. (2010), então, identificam três formas de ajuste que afetam a adaptação: (a) ajuste técnico; (b) ajuste cultural; e (c) ajuste político. Ajuste "técnico" indica em que medida os fundamentos tecnológicos e funcionais e as características incorporadas pela prática são compatíveis com as tecnologias e sistemas em uso por potenciais adotantes. Ajuste "cultural" mensura o quanto características culturais como valores e significado incorporado pela prática são compatíveis com a cultura organizacional, valores, crenças e normas dos potenciais adotantes. Ajuste "político" representa o grau de compatibilidade entre as características normativas implícitas e explícitas de uma prática e os interesses, estruturas de poder e agendas dos potenciais adotantes dessa prática. Como consequência, as características políticas incluem elementos coercitivos, bem como as normas, as estruturas de poder (formais e informais), coalizões e dependências de recurso que podem desencadear conflitos políticos e influenciar o modo como novas práticas são recebidas pela organização.

Ansari et al. (2010) também sugerem que os padrões de adaptação de uma prática são diferentes de acordo com a natureza do adotante: há os inovadores (primeiros a implementar a prática - early adopters), e os não inovadores (ou seguidores - later adopters). A pesquisa sobre difusão sugere que as diferenças entre adotantes precoces ou tardios devem ser levadas em conta em razão da natureza da interação entre fenômenos de nível populacional e fenômenos de nível organizacional (KENNEDY; FISS, 2009; ROGERS, 1995; TOLBERT; ZUCKER, 1983). Ansari et al. (2010) apresentam seis proposições sobre formas de ajuste (entre adoção e prática) e os padrões de adaptação de práticas:

Os inovadores geralmente experimentam uma falta de ajuste técnico entre as características da prática gerencial com a organização, e por isso tendem a implementar versões mais próximas da original, vez que possuem uma capacidade limitada de reduzir o desajuste. Dessa forma, a falta de ajuste técnico sugere um padrão de baixa adaptação entre os primeiros adotantes e sob medida entre os seguidores. Assim temos a primeira proposição do modelo do Ansari et al (2010):

Proposição 1 - quando os inovadores experimentam baixa adequação técnica entre as características da prática gerencial e da organização, vão implementar versões de maior fidelidade ao passo que os seguidores vão implementar versões de baixa fidelidade;

As incertezas sobre a prática que os inovadores vivenciam, bem como, a falta de ajuste técnico provoca o contraste entre as dimensões fidelidade e extensão. Dessa forma, quanto mais fiel ao seu protótipo original menos extensa será a adoção de uma prática e, por conseguinte, mais baixo será o padrão de adaptação, o que se traduz numa extensão menor. Dessa forma temos:

Proposição 2 - quando os inovadores experimentam baixa adequação técnica entre as características da prática gerencial e da organização, vão implementar versões menos extensas, ao passo que os seguidores vão implementar versões mais extensas; 
Quando a inovação gerencial é compatível com os valores, cultura e crenças vigentes na organização, diz-se que houve um ajuste cultural. As inovações não se difundem num vazio cultural, pelo contrário, quando importadas numa organização se deparam com atores e papéis definidos, comportamentos institucionalizados e legitimados. Esse desajuste inicial pode se constituir num obstáculo ao processo de difusão. De acordo com Ansari et al. (2010), ao ajuste cultural pouca atenção tem sido dada nos estudos sobre difusão de inovações gerenciais.

Os inovadores de uma prática não sofrem pressões de conformidade, gozando de mais liberdade para experimentá-la, defini-la e adaptá-la de modo que se adeque as suas características organizacionais. Entretanto, ao final do processo de difusão quando já existem modelos estabelecidos, as pressões de conformidade aumentam ocasionando a restrição na capacidade de os seguidores adaptarem e reduzirem o desajuste.

É possível que os seguidores implementem a prática gerencial de forma cerimoniosa e simbólica com o objetivo de mostrar conformidade com o meio externo, entretanto, no dia-adia da organização ela não seja utilizada. Esses adotantes mais tardios, são mais propensos a implementar versões de menor extensão.

Os inovadores são capazes de reduzir o desajuste por serem mais propensos a implementar a inovação gerencial de forma mais ampla, em face de sofrerem menos pressões de conformidade durante o estágio inicial, pois nesse estágio existe uma redução na necessidade de obtenção de benefícios. Os seguidores, por sua vez, em face das pressões de conformidade estarão menos envolvidos com o processo de redefinição da prática, aceitando-a da forma original, mesmo que o desajuste afete a adoção. Assim temos:

Proposição 3 - quando os inovadores experimentam baixa adequação cultural entre as características da prática gerencial e da organização, vão implementar versões de baixa fidedignidade, ao passo que os seguidores vão implementar versões de alta fidedignidade:

Por outro lado, os últimos a implementar a prática gerencial, os seguidores, não gozam de tanta liberdade para ajustá-la, vez que são pressionados a adotarem versões fiéis à original, o que proporciona pouca variação no processo de difusão. Ansari et al. (2010) então propôs:

Proposição 4 - quando os inovadores experimentam baixa adequação cultural entre as características da prática gerencial e da organização, vão implementar versões mais extensas, ao passo que os seguidores tendem a implementar versões menos extensas;

Por último, o ajuste político ocorre quando os interesses e agendas dos adotantes são compatíveis com as características normativas implícitas ou explicitas da inovação. Em face do número crescente de adeptos, o controle da aplicação da prática gerencial torna-se menos viável, o que permite aos seguidores adaptá-la reduzindo o desajuste com a organização. Diferentemente dos inovadores que adotam a prática gerencial fielmente à versão original. Assim temos:

Proposição 5 - quando os inovadores experimentam baixo ajuste político entre as características da prática gerencial e da organização, vão implementar versões de maior fidelidade, ao passo que os seguidores vão implementar versões de baixa fidelidade;

A crescente maturação torna os mecanismos de aplicação menos rigorosos, o que proporciona para os seguidores maiores oportunidades de implementar versões menos extensas da prática. Diferentemente dos inovadores que adotam a prática gerencial mais extensamente. Assim a proposição final do modelo do Ansari et al. (2010) é o seguinte: 
Proposição 6 - quando os inovadores experimentam baixo ajuste político entre as características da prática e da organização, vão implementar versões mais extensas, ao passo que os seguidores tendem a implementar versões menos extensas;

O modelo do Ansari et al. (2010), com suas 6 proposições, foi utilizado nesse artigo como uma "lente teórica" para suportar o desenvolvimento do modelo teórico desse estudo. Dessa forma, não se buscou "testar" essas 6 proposições nesse estudo. Nesse sentido, o que se pretende nesse estudo é que a partir de um modelo genérico proposto por Ansari et al. (2010), possamos estudar um fenômeno específico na área de contabilidade gerencial (no nosso caso a adaptação do BSC).

\subsection{Lógica institucional aplicada ao processo de adaptação}

A literatura sobre lógica institucional mostra que a adaptação de práticas se fundamenta no conceito de lógica institucional (LOUNSBURY, 2007, 2008; THORNTON; OCASIO, 2008; THORNTON; OCASIO; LOUNSBURY, 2012; SUJEEWA \& THARUSHA, 2017). Esta linha de pesquisa tem chamado a atenção para a importância de compreender as razões da variação nas práticas organizacionais e instiga a associar mudança institucional a tal variação (EZZAMEL et al., 2012). Lógica institucional pode ser entendida como sendo um composto de material vinculado e elementos simbólicos que trabalham juntos para constituir um tipo particular de ordem institucional. Como resultado, a lógica institucional compreende um conjunto altamente contingente de normas sociais que direcionam o comportamento para uma lógica de adequação (GUERREIRO et al., 2012). O pressuposto-chave da abordagem da lógica institucional é que os interesses, valores e identidades de indivíduos e organizações são influenciados e moldados pelas lógicas institucionais predominantes (THORNTON; OCASIO, 2008). Portanto, as lógicas institucionais formam a cognição e orientam a tomada de decisão, ajudando os atores organizacionais a se concentrar em um conjunto limitado de fatores e soluções - que são consistentes com as lógicas institucionais predominantes e que determinam o que é adequando e relevante para os atores organizacionais (THORNTON, 2002).

Estudos anteriores sobre mudança institucional têm apontado a importância da tensão institucional, com base na incompatibilidade das lógicas concorrentes (SEO; CREED, 2002; THORNTON; OCASIO, 2008). A literatura sobre lógica institucional tem mostrado que, como os campos são compostos por várias lógicas, a variação de uma prática é explicada por diferenças na orientação cognitiva e pelo debate sobre quais práticas são apropriadas (LOUNSBURY, 2007). Como resultado, heterogeneidade e agenciamento surgem a partir de contradições entre lógicas de ordem institucional diferentes que fornecem várias fontes de racionalidade (GUERREIRO et al., 2012). A literatura sobre lógica institucional apresenta quatro possíveis resultados da incompatibilidade de lógicas concorrentes: (1) a incorporação de elementos de uma nova lógica à lógica dominante; (2) a hibridização entre elementos da lógica anterior e da nova; (3) uma mudança da antiga lógica dominante para a lógica recentemente introduzida; e (4) a coexistência permanente de ambas as lógicas (LANDER; KOENE; LINSSEN, 2013). Com base nestas possíveis respostas ao conflito das lógicas, a literatura sobre lógicas institucionais tenta explicar a variação de práticas e seus processos de adaptação.

A abordagem da lógica institucional tem sido capaz de lançar luz sobre a questão da variação de práticas. Lounsbury (2007) conclui que a disseminação de uma nova prática é moldada por lógicas concorrentes que geram variação na adoção, comportamento e práticas de uma organização. No entanto, o presente trabalho argumenta que esta abordagem foca apenas nas características dos adotantes, ou seja, na lógica institucional incorporada à organização, mas negligência as características das práticas de difusão. Acredita-se que a abordagem da lógica institucional não pode lograr pleno êxito ao explicar a adaptação de práticas, uma vez 
que tanto a lógica institucional incorporada ao adotante quanto a difusão precisam ser consideradas.

Portanto, a fim de superar essa limitação, buscou-se ampliar a existente literatura sobre lógica institucional na adaptação de práticas em nível intraorganizacional a partir da visão de Ansari et al. (2010), de que os padrões específicos de adaptação de uma prática externa dependerão do ajuste entre a prática e organização adotante da prática. Em outras palavras, propõe-se que: a adaptação de prática (similaridade e extensão) será determinada pelo ajuste entre a lógica institucional dominante incorporada à organização e a lógica institucional incorporada na prática que está sendo difundida (versão prototípica). Ao adotar esta abordagem, entende-se a prática como um "tipo de instituição" (LOUNSBURY; CRUMLEY, 2007; LOUNSBURY; VENTRESCA, 2003) que é formado por um conjunto específico de lógicas institucionais.

No entanto, Thornton et al. (2012) destacam que o conceito de lógica institucional é indiscutivelmente difícil de definir e ainda mais difícil de aplicar de forma analiticamente útil. Como consequência, para operacionalizar a proposição acima de forma analiticamente útil e fornecer um modelo conceitual para a compreensão de padrões de adaptação de práticas de contabilidade gerencial em nível intraorganizacional, associou-se à literatura sobre lógica institucional ao modelo de Ansari et al. (2010), sugerindo que a lógica institucional incorporada ao adotante de uma prática e à difusão de uma prática pode ser identificada ao analisar as características técnicas, culturais e políticas do adotante e da prática implementada.

Utilizou-se Thornton et al. (2012) para justificar esta abordagem. Eles argumentam que as práticas e as identidades são as instâncias materiais da lógica institucional e estes dois conceitos guiarão atores organizacionais para a dinâmica intraorganizacional da tomada de decisão, sensemaking e mobilização coletiva. Uma premissa-chave do modelo teórico de Thornton et al. (2012) é que lógica institucional, práticas e identidades organizacionais estão fundamentalmente inter-relacionadas. Como resultado, Thornton et al. (2012) conceituam identidade organizacional e práticas como os vínculos conceituais chave entre a lógica institucional e os processos intraorganizacionais.

Partindo desta visão para explicar o processo de adaptação de uma prática externa em nível intraorganizacional, argumenta-se, no presente estudo, que a lógica institucional incorporada na prática em difusão e a organização adotante materializam-se mediante as características da prática externa e a identidade organizacional do adotante. Utiliza-se aqui a definição de identidade organizacional fornecida por Albert e Whetten (1985), que afirmam que a identidade organizacional é a característica central, distintiva e duradoura de uma organização. Sugere-se que estas características distintivas podem ser divididas por razões analíticas em três categorias (como proposto por Ansari et al. (2010) e Oliver (1992)): características técnicas, culturais e políticas.

\section{BALANCED SCORECARD (BSC)}

\subsection{Versão prototípica do BSC e processo de adaptação}

O Balanced Scorecard evoluiu de forma contínua, capturando e integrando novas ideias e ferramentas (BARNABÈ; BUSCO, 2012; CHENG; HUMPHREYS, 2012; KAPLAN, 2009, 2012). Na primeira modelagem (KAPLAN; NORTON, 1992, 1996), o BSC foi principalmente uma ferramenta destinada à medição de desempenho. O BSC pode ser visto como um sistema de medição de desempenho que combina a utilização de indicadores financeiros e não financeiros, informações internas/externas e tempestivas/intempestivas de forma coerente. Kaplan e Norton (1992) vincularam o BSC a um "painel de controle de métricas", e em seguida o painel foi substituído pela imagem de um "simulador de voo" (KAPLAN; NORTON, 1996). 
Mais tarde, Kaplan e Norton apresentam o BSC como não apenas uma coleção de medidas de desempenho relevantes, mas como uma ferramenta gerencial e um processo que desempenha um papel na melhoria da performance organizacional por meio do apoio à implementação de estratégia (KAPLAN; NORTON, 2001, 2004, 2006). Como resultado, os proponentes do BSC acreditam que sua implementação reforça a estratégia da organização e alinha os recursos com os objetivos estratégicos (CHENG; HUMPHREYS, 2012). A intenção estratégica da gerência é comunicada a toda a organização por meio do BSC, ajudando assim a alinhar os recursos com as estratégias (CRABTREE; DEBUSK, 2008). Kaplan (2010) conclui que desde o primeiro artigo sobre o BSC, em 1992, o conceito do Balanced Scorecard foi estendido e ampliado para uma ferramenta de gestão de descrição, comunicação e implementação da estratégia.

Apesar de sua evolução ao longo dos anos, duas características do BSC permaneceram inalteradas desde a primeira publicação em 1992. Primeiro, Kaplan e Norton mantiveram a mesma taxonomia, como resultado, o BSC hoje ainda mantém as mesmas quatro perspectivas que tinha em 1992 (financeira, cliente, processos internos e aprendizagem e crescimento). Em segundo lugar, Kaplan e Norton mantiveram ao longo do tempo a mesma lógica de causa-efeito que surgiu com o primeiro BSC (COOPER; EZZAMEL; QU, 2017).

O BSC é baseado em uma quádrupla categorização das medidas de desempenho compreendendo: financeiro, cliente, processos internos do negócio e aprendizagem e crescimento no desempenho organizacional. Com base na visão da organização e na estratégia, objetivos e medidas de desempenho são estabelecidas para cada uma destas quatro perspectivas. Em termos empresariais, a perspectiva financeira identifica como uma companhia deseja ser vista por seus acionistas. A perspectiva do cliente reflete como deseja ser vista pelos clientes. A perspectiva de processos internos do negócio indica as áreas em que a empresa tem de ser particularmente competente a fim de satisfazer seus clientes e acionistas. A perspectiva de aprendizado e crescimento envolve desenvolvimentos gerenciais que a empresa precisa implementar para que a estratégia e a visão possam ser alcançadas (NORREKLIT; MITCHELL, 2007). Portanto, as medidas de desempenho devem representar um equilíbrio entre medidas de desempenho externo relativas a acionistas e clientes, e as medidas internas do processo crítico de negócios, inovação, aprendizado e crescimento.

No contexto do Balanced Scorecard, relações de causa entre as perspectivas desempenham um papel central (AGOSTINO; ARNABOLDI, 2012; JOHANSON et al., 2006; TAYLER, 2010). Norreklit e Mitchell (2007) pontuam que sem esta característica não existe um "verdadeiro" BSC. O BSC inclui medidas de desempenho financeiras e não financeiras que interligam as quatro perspectivas em uma relação de causa e efeito. A relação causal entre as quatro perspectivas pressupõe que as medidas de aprendizado e crescimento direcionam as medidas de processos internos do negócio. Estas últimas, então, orientam as medidas do ponto de vista do cliente e, por sua vez, as medidas do cliente conduzem às medidas de resultado financeiro (CARDINAELS; VAN VEEN-DIRKS, 2010; WONG-ON-WING et al., 2007).

Apesar da popularidade do Balanced Scorecard (particularmente, na literatura profissional), uma gama de críticas negativas ao BSC tem aparecido na literatura acadêmica (JAZAYERI; SCAPENS, 2008). Malmi (2001) ressalta que isto é apenas um número relativamente pequeno do que aparenta ser BSCs que estão fora do formato que representaria a plena aplicação do BSC de Kaplan e Norton. Devido à complexidade da operacionalização dos conceitos do BSC e sua constante inovação, o BSC tem sido classificado em três modalidades diferentes (LEE; YANG, 2011):

- Tipo I: um sistema que combina medidas financeiras e não financeiras em quatro perspectivas, a saber, financeira, clientes, processos internos e aprendizado e crescimento. O objetivo do BSC é alocar recursos e comunicar o progresso em 
direção a objetivos estratégicos e avaliar o desempenho da organização. As organizações podem adotar indicadores de desempenho que englobem as relações de causa e efeito que possam existir entre seus objetivos estratégicos, medidas e resultados (LEE; YANG, 2011).

- Tipo II: um sistema que considera medidas financeiras e não financeiras e, além disso, descreve estratégias e medidas usando as relações de causa-efeito. Dadas estas características, o atingimento dos objetivos estratégicos é mais atrativo para os gerentes, já que eles são recompensados com base no cumprimento das metas financeiras e não financeiras (LEE; YANG, 2011).

- Tipo III: um sistema que se concentra na implementação da estratégia, definindo objetivos, planos de ação, resultados e incentivos correlacionados ao BSC. Este sistema também inclui um sistema de medição de desempenho integrado e relações de causa-efeito entre estratégias e medidas (LEE; YANG, 2011).

Neste trabalho, procura-se explicar variações da forma como o Balanced Scorecard, enquanto uma prática de contabilidade gerencial, se adapta a uma organização avaliando-se a similaridade e a extensão (as dimensões da adaptação) da implementação do BSC em relação ao seu "protótipo". Considera-se no presente artigo que a versão prototípica do BSC derive dos livros de Kaplan e Norton (1996, 2001, 2004, 2006, 2008). Essa literatura fornece uma modelo genérico do BSC que compreende quatro características principais: (1) um sistema que combina medidas de desempenho financeiras e não financeiras; (2) um sistema que é estruturado em quatro perspectivas: financeira, cliente, processos de negócios internos e aprendizado e crescimento (a taxonomia BSC); (3) um sistema baseado nas relações de causa-efeito entre as medidas que ligam as quatro perspectivas; e (4) um sistema que se concentra na comunicação e implementação da estratégia. Para a versão protótipo do BSC, entendemos estratégia conforme definido por Kaplan e Norton (1996), que afirmam que a estratégia é um conjunto de hipóteses sobre causa e efeito.

Sugere-se neste trabalho que a "similaridade" do modo como o Balanced Scorecard se adapta a uma organização pode ser avaliada com base nas quatro características supracitadas do "protótipo" do BSC. No caso do BSC, adaptação de alta similaridade incluiria todos os quatro elementos acima, apresentados nos livros de Kaplan e Norton, modelos similares e medidas genéricas, ao passo que a adaptação de baixa-similaridade não reforçaria todas as quatro características, sendo o nível de modificações e personalização elevado (ver Figura 1). Apesar de sugerimos nesse artigo que a similaridade pode ser analisada com base nesses quatro pontos, e não se defende que esta análise pode ser realizada de forma linear, ou seja, mediante uma análise do tipo check-list. Ao aplicar esta abordagem, uma cuidadosa consideração e análise dos quatro pontos deve ser efetuada no sentido de identificar se a organização implementou os quatro aspectos do BSC de maneira similar ao que foi apresentado por Kaplan e Norton em seus livros e artigos. Como resultado, uma pesquisa qualitativa, com base em um único caso parece uma escolha natural para estudar o processo de adaptação do BSC em nível intraorganizacional, uma vez que esta abordagem é capaz de fornecer satisfatoriamente os dados necessários para avaliar o quanto a implementação do BSC se desvia do seu protótipo original.

Com relação à dimensão da "extensão" da adaptação, sugere-se que pode ser avaliada pelo grau em que as quatro características do Balanced Scorecard são implementadas na organização. Uma adaptação de alta-extensão significa uma aplicação abrangente das práticas do BSC na organização, enquanto uma adaptação de baixa-extensão significa uma aplicação não tão abrangente das práticas do BSC na organização. Especificamente, supõe-se que uma adaptação de baixa-extensão dos princípios do BSC leva ao BSC tipo I (Figura 1), enquanto que uma adaptação de alta-extensão das práticas do BSC leva ao BSC Tipo III (idem). 

PARA ESTUDAR A ADAPTAÇÃO DO BSC

Figura 1 - Dimensões de adaptação do Balanced Scorecard

\begin{tabular}{|c|c|c|c|}
\hline \multicolumn{4}{|c|}{ Similaridade } \\
\hline$\uparrow$ & Alta & \multicolumn{2}{|l|}{ Verdadeiro para a "versão protótipo" do BSC } \\
\hline$\downarrow$ & Baixa & \multicolumn{2}{|l|}{ Falso para a "versão protótipo" do BSC } \\
\hline \multicolumn{4}{|c|}{ Extensão } \\
\hline$\uparrow$ & Alta & Amplamente implementado & $\begin{array}{l}\text { BSC tipo III } \\
\text { BSC tipo II }\end{array}$ \\
\hline$\downarrow$ & Baixa & Não amplamente implementado & BSC tipo I \\
\hline
\end{tabular}

Fonte: Elaboração Própria

\subsection{Lógica institucional e características técnicas, culturais e políticas do BSC}

Como já discutido, uma prática externa pode ser analisada como um "tipo" de instituição (LOUNSBURY; VENTRESCA, 2003) moldada por lógicas institucionais particulares. No contexto da forma prototípica do Balanced Scorecard, sugere-se que o modelo básico do BSC foi incorporado e moldado pela lógica de gestão dos Estados Unidos da América (EUA) (ver Quadro 1 para as normas e racionalizações associadas a esta lógica). O “protótipo" do BSC foi incorporado pelas lógicas institucionais presentes em uma grande corporação no contexto dos EUA (BOURGUIGNON; MALLERET; NØRREKLIT, 2004; JOHANSON et al., 2006). As raízes do BSC podem ser rastreadas a partir das crescentes preocupações com o declínio da indústria de transformação dos EUA na década de 1980, que sem dúvida foi agravada pela alta dependência de indicadores de desempenho financeiro de curto prazo (MODELL, 2009).

Quadro 1 - Lógica institucional incorporada à forma prototípica do BSC

\begin{tabular}{|l|l|}
\hline \multicolumn{1}{|c|}{ Características } & \multicolumn{1}{c|}{ Lógica de gestão dos EUA } \\
\hline Fontes de identidade & Funções burocráticas. \\
\hline Fontes de legitimidade & Posição de mercado da empresa; preço da ação. \\
\hline Fontes de autoridade & Alta Administração. \\
\hline Base de normas & Concorrência; eficiência; “contrato justo” entre superior e subordinados. \\
\hline Base de atenção & Posicionamento na indústria. \\
\hline Base da estratégia & Criação de valor. \\
\hline
\end{tabular}

Fonte: Adaptada de Thornton et al. (2005) e Ezzamel et al. (2012)

O Balanced Scorecard tem um forte ethos, derivado da literatura de negócios dos EUA, em particular, derivada da Harvard Business School (NORREKLIT; MITCHELL, 2007). Kaplan (2009) discutiu os fundamentos conceituais do BSC e explicou que o BSC foi influenciado pelos escritores de negócios americanos, em particular, Michael Porter, Peter Drucker e Robert Anthony. Kaplan também explicou a influência da literatura relativa à qualidade, à gestão enxuta, economia financeira e teoria dos stakeholders, no desenvolvimento da modelo básico do BSC. O BSC também tem uma fundamentação ideológica que representa uma relação contratual "justa" entre superiores e subordinados, baseados em uma ideologia individualista e meritocrática, que é condizente com os estilos de gestão dominantes nos EUA (BOURGUIGNON et al., 2004; NØRREKLIT; NØRREKLIT; MELANDER, 2006).

Em resumo, a lógica gerencial dos EUA fornece os princípios básicos para uma técnica de negócios que compreende os seguintes pontos (CUNLIFFE, 2009; TAYLOR, 1999; ZEFF, 2008): (a) os gerentes são especialistas qualificados que têm o direito de atuar como agentes perante proprietários e acionistas; (b) a gestão trabalho caracteriza-se pela racionalidade e neutralidade; (c) a eficiência deve ser perseguida por meio da minimização dos custos e da 
maximização do lucro e da produtividade; (d) os gerentes têm o direito de tomar decisões e dar instruções aos funcionários, sem buscar consenso; (e) gestores agem alinhados ao bem comum e são os instrumentos e os administradores do capitalismo; e (f) técnicas gerenciais devem ser usadas para resolver problemas, aumentar a eficiência e criar valor para a organização.

Partindo de Ansari et al. (2010), sugere-se que a adaptação do Balanced Scorecard é uma resposta à falta de ajuste entre a lógica de 'gestão' dos EUA incorporada pelo BSC e a lógica institucional incorporada por uma organização adotante do BSC. Como já mencionado, para fins analíticos de explicar a adaptação intraorganizacional do processo de adaptação de uma prática de contabilidade gerencial externa, entendemos que as características do BSC podem expressar a lógica institucional incorporada à prática. Estas características são divididas em três categorias: características técnicas, culturais e políticas. O Quadro 2 resume as características do BSC:

\begin{tabular}{|c|c|}
\hline Categorias & Características do BSC \\
\hline Técnica & $\begin{array}{l}\text {-Processos passo a passo. } \\
\text {-Integração com outros sistemas. } \\
\text {-Forte apoio dos sistemas de TI }\end{array}$ \\
\hline Cultura & $\begin{array}{l}\text {-Equilíbrio entre medidas/desempenho financeiras e não financeiras. } \\
\text {-Alinhamento dos objetivos estratégicos. } \\
\text {-Abordagem das partes interessadas com foco na maximização do valor dos acionistas. } \\
\text {-Ethos das grandes corporações. }\end{array}$ \\
\hline Política & $\begin{array}{l}\text {-Abordagem apolítica. } \\
\text {-Sistema hierárquico e top-down. } \\
\text {-Gerentes como otimizadores de valor neutro. }\end{array}$ \\
\hline
\end{tabular}

Fonte: Elaborado pelos autores

As principais características técnicas do Balanced Scorecard compreendem os seguintes aspectos: processos passo a passo; integração com outras ferramentas de gestão; e um forte apoio dos sistemas de TI. Primeiro, a operacionalização do BSC é ditada por uma abordagem normativa apresentada nos textos por Kaplan e Norton (1992, 1996, 2001, 2004, 2006, 2008). Nørreklit et al. (2012) ressaltam que, quando Kaplan e Norton descrevem o processo de gestão do BSC, seus livros são dominados por processos unidirecionais em etapas. Por exemplo, o protótipo do BSC tem a organização global do processo que se segue cinco etapas: mobilizar a mudança por meio da liderança executiva; traduzir a estratégia; alinhar a organização à estratégia; motivar os empregados a realizar a estratégia no seu trabalho cotidiano; governar para tornar a estratégia um processo contínuo (KAPLAN, 2009; KAPLAN; NORTON, 2001).

A segunda característica é que o BSC é uma tecnologia aberta que deve ser integrada a outras ferramentas de gestão. O BSC é forte em sua capacidade de ser integrado com ideias de gestão existentes, tais como a análise de valor do acionista e o valor econômico adicionado (EVA); o modelo de negócios da Fundação Europeia para a Gestão da Qualidade (EFQM); Custeio Baseado em Atividades (ABC); Orçamento; Gestão da Qualidade Total (TQM); Gestão de Riscos; e Processo de Hierarquia Analítica (AHP) (ABDEL-KADER; MOUFTY; LEAL, 2011; AGOSTINO; ARNABOLDI, 2012; SUNDIN; GRANLUND; BROWN, 2010). Finalmente, o BSC precisa de forte apoio dos sistemas de TI (tecnologia da informação). Desta forma, Kaplan e Norton são fortes defensores do uso combinado de sistemas de tecnologia com o BSC (KAPLAN; NORTON, 2001; WONG; CHIANG; MCLEOD, 2009).

Em termos de características culturais do Balanced Scorecard, foram identificados quatro aspectos principais. Primeiro, o BSC como um sistema de planejamento e controle de gestão abrange medições financeiras e não financeiras (KAPLAN, 2009). Kaplan e Norton (1996) defendem que os sistemas de gestão e valores de uma organização devem respeitar o 
"equilíbrio" entre medidas financeiras e não financeiras, entre desempenho de curto prazo e de longo prazo, e entre medidas ultrapassadas (resultado) e medidas vanguardistas (pilotos).

A segunda característica cultural é que o BSC se centra no alinhamento com o objetivo estratégico, o qual enfatiza o alinhamento do desempenho gerencial com os objetivos estratégicos primordiais da organização. Alinhamento estratégico objetivo se alcança mediante o gerenciamento das relações causais entre os direcionadores do desempenho subjacentes (CARDINAELS; VAN VEEN-DIRKS, 2010; CHENG; HUMPHREYS, 2012). Em terceiro lugar, o BSC tem uma abordagem relacional, com foco na maximização do valor dos acionistas no longo prazo. O BSC destaca a importância dos stakeholders para a gestão de desempenho, e reconhece a importância de satisfazer os clientes e atingir a eficiência operacional.

Apesar disso, o BSC reconhece as partes interessadas (especialmente os clientes e funcionários), e é considerado um modelo voltado aos acionistas (JAZAYERI; SCAPENS, 2008) tendo como seu objetivo final a maximização do valor dos acionistas no longo prazo (BOULIANNE, 2008). Finalmente, o BSC tem um ethos corporativo. O BSC foi desenvolvido inicialmente para empresas do setor privado. Os originais escritos por Kaplan e Norton (1992, 1996) têm em seu público-alvo grandes empresas. Os usuários ou pretensos usuários mencionados nos textos são principalmente bancos e empresas de tecnologia de tamanho substancial (JOHANSON et al., 2006).

Foram identificadas três principais características políticas no modelo básico do Balanced Scorecard. Primeiro, o BSC adota uma abordagem "apolítica" (MODELL, 2012). A concepção do sistema do BSC é retratada como um exercício politicamente neutro, dominado pela equipe da alta gestão, sem muito questionamento sobre a legitimidade das agendas estratégicas ou sobre o poder dos gestores para executá-las. A difusão e a implementação do BSC é vista a partir de uma visão funcionalista, traçando as justificativas para a adoção de antecedentes econômicos, técnicos e estruturais. (SPECKBACHER et al., 2003). Em segundo lugar, o BSC retrata os gerentes como otimizadores de valor neutro. No âmbito do BSC, a principal tarefa gerencial é vista como balancear os múltiplos aspectos de desempenho para salvaguardar a sobrevivência organizacional a longo prazo (MODELL, 2012).

Figura 2 - Modelo conceitual do processo de adaptação do BSC em nível intraorganizacional

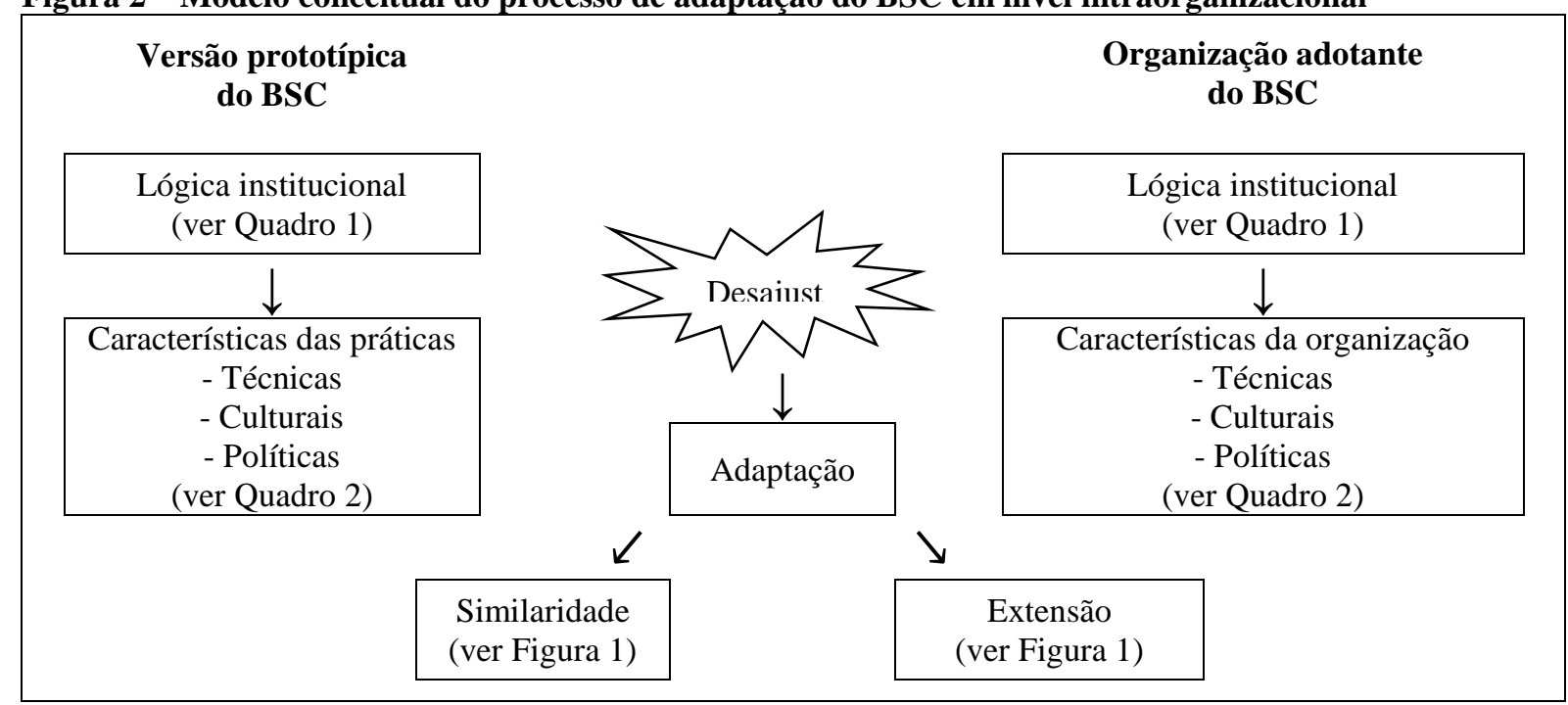

Fonte: Elaborado pelos autores

Em terceiro lugar, o BSC é um sistema hierárquico e top-down (NORREKLIT, 2000; NORREKLIT; MITCHELL, 2007; WONG-ON-WING et al., 2007). O BSC tem uma abordagem "top-down" "em que altos executivos definem os objetivos no mapa estratégico e as medidas relacionadas ao BSC correspondente para aqueles que estão em níveis mais baixos 
da hierarquia organizacional" (KAPLAN, 2012, p. 541-542). Por conseguinte, a implementação do BSC é vista como uma materialização mediante um processo top-down, em que as prioridades estratégicas formuladas pela diretoria são comunicadas para baixo por meio da hierarquia organizacional. Os gerentes de nível inferior e os funcionários são principalmente descritos como aspectos a serem conciliados com objetivos estratégicos de superação por meio de treinamento e feedback contínuo no processo de fomentar a consciência estratégica na organização (MODELL, 2009, 2012; NØRREKLIT et al., 2012).

Com base em Ansari et al. (2010), sugere-se no presente trabalho que a adaptação do Balanced Scorecard é uma resposta à falta de ajuste entre a lógica gerencial dos EUA incorporada ao BSC e a lógica institucional incorporada à organização adotante do BSC. A Figura 2 mostra o modelo conceitual proposto neste estudo. Com base em Ansari et al. (2010) e na literatura relativa à lógica institucional, argumenta-se que as lógicas institucionais incorporadas pela organização adotante e pelo BSC podem ser identificadas mediante a análise das práticas e características técnicas, culturais e políticas da organização. As incompatibilidades (desajustes) entre as características técnicas, culturais e políticas da organização e a prática de difusão irão acionar mecanismos diferentes e os padrões de adaptação em termos de suas duas dimensões: similaridade e extensão.

\section{CONCLUSÃO}

Este artigo dispôs-se a discutir a adaptação das práticas de contabilidade gerencial em nível intraorganizacional focando o BSC. Para tanto, o estudo propõe um modelo conceitual para examinar a adaptação do BSC em nível intraorganizational com base na literatura da lógica institucional e no modelo proposto por Ansari et al. (2010). Embora a literatura contábil sobre difusão tenha aprofundado o conhecimento sobre como as práticas são transferidas por meio de populações de organizações, essa literatura não examinou de forma profunda o que ocorre com as práticas introduzidas durante e após a adoção (BURKERT; LUEG, 2013). Acredita-se que esse enfoque sobre o nível de população tem suas limitações, uma vez que assume que as práticas são em grande parte uniformes e imutáveis (EZZAMEL et al., 2012), o que desviou a atenção de como as práticas variam ao longo do processo de difusão e quais os fatores que podem afetar o processo de adaptação. Neste trabalho, foram desafiados o raciocínio tradicional e social referente à difusão nas organizações, argumentando-se que a adaptação é a norma e não a exceção. Como resultado, as características das práticas de difusão serão objeto de negociação e mudança durante o processo de difusão. Como consequência, os atores organizacionais encontrarão dificuldades para executar cálculos racionais sobre a relação custo-benefício e conflitos de adoção quando o significado da prática de difusão ainda esteja em curso.

Estudos com base na literatura da lógica institucional foram além das explicações sobre adoção ou não adoção para destrinchar como práticas de difusão são transformadas e variam como na medida em que espalham (EZZAMEL et al., 2012; GUERREIRO et al., 2012; HYVÖNEN et al., 2009; LESSA et al., 2013; LOUNSBURY, 2007). No entanto, esta literatura também se centrou principalmente sobre os efeitos da lógica institucional por meio dos campos institucionais. Tem havido pouco esforço para catalogar e explorar o papel da lógica institucional no seio de organizações (THORNTON et al., 2012). Como consequência, falta ainda um quadro conceitual na literatura contábil para identificar padrões de adaptação de práticas de contabilidade gerencial em todo o processo de difusão em nível intraorganizacional.

No presente estudo, argumenta-se que o processo de adaptação dependerá do ajuste entre a prática e a empresa adotante (ANSARI et al., 2010), assim a interação entre os fatores do lado da demanda (fatores da organização) e os fatores do lado da oferta (características de prática) suporta a explicação sobre adaptação da prática durante o processo de difusão (FISS et al., 2012). Com base neste argumento, também se identifica outra limitação importante na literatura da lógica institucional sobre a adaptação de práticas, que é o fato de que essa literatura 
centra-se na procura de fatores que afetam a adaptação da prática com a visão subjacente de que a difusão de uma prática é moldada por lógicas concorrentes enfrentadas pelo adotante.

A fim de superar as limitações acima na literatura sobre a difusão e adaptação das práticas de contabilidade gerencial, em especial com base na lógica institucional em nível intraorganizacional, e de colocar "lógicas institucionais" como o mais amplo modelo cultural que fornece atores organizacionais com designações voltadas para resultado e princípios (PALOMO; SANTOS, 2010); e, consequentemente, moldar o processo de adaptação de uma prática externa em uma organização, propõe-se que: adaptação de uma prática (similaridade e extensão) será determinada pelo ajuste entre as lógicas institucionais dominantes incorporadas na organização e a lógica institucional incorporada na prática difundida (versão prototípica). A principal contribuição deste estudo, portanto, consiste em salientar o lado dos fatores da oferta (lógica de prática externa) que influenciam o processo de adaptação de uma prática externa em uma organização. Essa influência não foi reconhecida de forma consistente pela literatura da lógica institucional.

Para operacionalizar a proposição acima de forma analiticamente útil, tomou-se por base a visão de Thornton et al. (2012) de que práticas e identidade organizacional são as instâncias materiais da lógica institucional. Depois disso, vinculou-se esta visão ao modelo teórico de Ansari et al. (2010), argumentando que a prática de difusão e a identidade organizacional podem ser analisadas e divididas em três categorias: características técnicas, culturais e políticas. Como resultado, por razão analítica, defende-se que as incompatibilidades entre as características técnicas, culturais e políticas da organização e a prática de difusão irão acionar mecanismos diferentes e os padrões de adaptação em termos de similaridade e extensão da forma prototípica até a prática. Ao adotar este enquadramento teórico, foi possível operacionalizar a principal proposição e fornecer um modelo para identificar padrões de adaptação de práticas de contabilidade gerencial em todo o processo de difusão em nível intraorganizacional.

Nesse artigo modificamos o foco convencional sobre os efeitos das lógicas institucionais no processo de adaptação de práticas no campo inter-orgizacional, para enfocar nos efeitos das lógicas institucionais no processo intra-organizacional de adaptação de práticas de contabilidade gerencial. Baseando-se na literatura sobre lógicas institucionais e incorporando os principais achados da literatura de adaptação de práticas gerenciais, suportamos o modelo conceitual proposto nesse estudo e sugerimos que uma das principais razões por que uma organização adaptar (ou não adaptar) uma prática implementada é porque as características da prática não se encaixam nas características da organização (ROGERS, 1995, ANSARI et al., 2010). De fato, Ax e Greve (2017) pedem mais pesquisas que visem explicar e entender como o ajuste ou desajuste entre as características de uma organização e os valores e crenças associados às práticas de contabilidade gerencial influenciam a implementação e o uso dessas práticas nas organizações. Respondemos a esse chamado fornecendo um modelo conceitual que mostra que a adaptação da prática de contabilidade gerencial (similaridade e extensão) é influenciada pelo desajuste entre as lógicas institucionais dominantes embutidas em uma organização e as lógicas institucionais embutidas em uma prática em difusão (versão prototípica).

O modelo conceitual proposto possui um importante condicionante: lógicas institucionais não são parâmetros fixos com aplicabilidade universal. Em vez disso, as lógicas dependem das interpretações dos atores organizacionais. As lógicas institucionais não são inerentemente conflitantes ou complementares, mas os atores organizacionais podem percebêlas dessa maneira (SMETS et al., 2015). De fato, múltiplas lógicas produzem conflitos internos em algumas organizações, mas se tornam perfeitamente integradas em outras empresas (BESHAROV; SMITH, 2014). SMETS et al. (2015) explicam que a natureza do trabalho e a natureza das demandas institucionais influenciam como a complexidade institucional é vivenciada e percebida em uma organização. Como resultado, existem maneiras heterogêneas 
pelas quais várias lógicas podem se manifestar dentro das empresas. Portanto, mais pesquisas podem se concentrar em como os atores organizacionais percebem a lógica institucional desajustada entre uma prática e uma organização.

Especificamente, este trabalho contribui para a crescente literatura sobre o Balanced Scorecard (HOQUE, 2014), permitindo uma melhor compreensão e sugerindo um explicação teórica para o processo de modificação e adaptação do BSC em nível intraorganizacional. De acordo com Hoque (2014), cerca de 40\% das pesquisas sobre o BSC, publicadas em revistas de contabilidade, está relacionada com as questões da sua adoção, implementação e difusão. No entanto, este corpo de pesquisa é amplamente baseado no estrato de população que se concentra em como e por que o BSC foi transferido e difundido entre as populações de organizações. Além disso, Dechow (2012) aponta que a maioria dos estudos sobre o Balanced Scorecard explorou os propósitos para os quais os gerentes usam e adotam o Balanced Scorecard. Como consequência, ainda há uma grande falta de conhecimento sobre o que ocorre com o Balanced Scorecard durante e após sua adoção e os fatores que podem afetar seu processo de adaptação.

Embora pesquisas futuras sobre o processo de adaptação de práticas de contabilidade provavelmente se beneficiem da adoção de uma abordagem qualitativa e multinível, o modelo proposto pode trazer importantes implicações para os estudos tradicionais de difusão em larga escala, baseados em métodos quantitativos. Tais estudos tendem principalmente a atribuir a capacidade adaptativa das organizações a quem adota cedo (inovadores) ou tardiamente (seguidores) uma inovação (ver ANSARI et al., 2010; MALMI, 1999). A lógica por trás desse argumento é que os adotantes iniciais têm oportunidades de influenciar as inovações em bases relativamente racionais, enquanto os adotantes posteriores tendem a seguir uma abordagem menos racional e adotar versões altamente padronizadas sustentadas por convenções sociais. No entanto, essas distinções analíticas podem nem sempre ser as mais relevantes para explicar variações em uma maior população de organizações. Isto é especialmente verdade quando o uso de inovações constitui um requisito obrigatório e as diferenças no momento da adoção são limitadas, como é frequentemente no caso em indústrias reguladas e no setor público (LAPSLEY; WRIGHT, 2004; HOPPER; MAJOR, 2007). Para explicar o papel das adaptações como um fenômeno mais contínuo, os pesquisadores podem complementar a distinção entre adotantes precoces e tardios com algum reconhecimento de que as organizações adotantes são capazes de influenciar inovações durante o processo de difusão.

No entanto, investigar o processo de adaptação no nível intraorganizational, coloca certos desafios metodológicos aos estudos de difusão baseados em dados quantitativos. Pode ser possível que estudos quantitativos considerem os efeitos no processo de adaptação incluindo algumas medidas indiretas ou proxies que não representem adequadamente tais efeitos. É improvável que tais medidas capturem todas as implicações do processo de adaptação como um processo mais contínuo e possam subrepresentar a complexidade e a natureza dinâmica desse fenômeno. Assim, parece haver um forte argumento para complementar estudos sobre adaptação em larga escala com pesquisas qualitativas sobre como as adaptações são realizadas. Isso poderia implicar investigações historicamente informadas sobre como o processo de adaptação de práticas de contabilidade gerencial são estabelecidos, bem como estudos de caso comparativos em algumas organizações cuidadosamente selecionadas. Assim, concordamos com o apelo de Ansari et al. (2010) no sentido de incentivar a utilização de pesquisas baseadas em métodos mistos para a investigação do processo de adaptação - o que possibilita captar a complexidade do processo de adaptação a nível intra e inter-organizacionais.

Em suma, este artigo explora o papel das lógicas institucionais expressos em termos dos desajustes das características técnicas, culturais e políticas entre o Balanced Scorecard e as organizações no processo de adaptação dessa prática. Ao fazer isso, são fornecidas novas visões sobre os mecanismos pelos quais as características técnicas, culturais e políticas conflitantes entre prática e organização adotante influenciam os padrões de adaptação da prática no nível 
intraorganizacional. $\mathrm{O}$ presente estudo, portanto, sugere que o modelo conceitual aqui apresentado fornece uma maneira analiticamente útil de estudar e explicar o processo de adaptação do Balanced Scorecard no âmbito intraorganizational.

\section{REFERÊNCIAS}

ABDEL-KADER, M. G.; MOUFTY, S.; LAITINEN, E. K. Balanced Scorecard development: a review of literature and directions for future research. In: ABDEL-KADER, M. G. (Ed.). Review of Management Accounting Research. New York: Palgrave Macmillan, 2011. p. 214-239.

ABRAHAMSON, E. Managerial fads and fashions: the diffusion and rejection of innovations. The Academy of Management Review, v. 16, n. 3, p. 586-612, 1991. $285,1996$.

Management fashions. The Academy of Management Review, v. 21, n. 3, p. 254-

AGOSTINO, D.; ARNABOLDI, M. Design issues in Balanced Scorecards: rhe "what" and "how" of control. European Management Journal, v. 30, n. 4, p. 327-339, 2012.

ALBERT, S.; WHETTEN, D. Organizational identity. Research in Organizational Behavior, v. 7, p. 263-295, 1985.

ANSARI, S. M.; FISS, P. C.; ZAJAC, Z. J. Made to fit: how practices vary as they diffuse. Academy of Management Review, v. 35, n. 1, p. 67-92, 2010.

AX, C.; BJORNENAK, T. Management accounting innovations: origins and diffusion. In: HOPPER, T.; SCAPENS, R. W.; NORTHCOTT, D. (Eds.). Issues in management accounting. 3rd ed. Harlow: Financial Times Prentice Hall, 2007. p. xxii, 458.

AX, C; GREVE, J. Adoption of management accounting innovations: Organizational culture compatibility and perceived outcomes. Management Accounting Research, v. 34, p. 59-74, 2017.

BARNABÈ, F.; BUSCO, C. The causal relationships between performance drivers and outcomes: reinforcing balanced scorecards' implementation through system dynamics models. Journal of Accounting \& Organizational Change, v. 8, n. 4, p. 528-538, 2012.

BESHAROV, M. L.; SMITH, W. K. Multiple institutional logics in organizations: Explaining their varied nature and implications. Academy of management review, v. 39, n. 3, p. 364$381,2014$.

BOULIANNE, E. Examining the construct validity of the balanced scorecard using multitraitmultimethod matrix. In: EPSTEIN, M. J.; MANZONI, J. F. (Eds.). Performance measurement and management control: measuring and rewarding performance. Bingley: Emerald JAI, 2008. p. xiv, 356.

BOURGUIGNON, A.; MALLERET, V. R.; NØRREKLIT, H. The American balanced scorecard versus the French tableau de bord: the ideological dimension. Management Accounting Research, v. 15, n. 2, p. 107-134, 2004. 
BOXENBAUM, E.; JONSSON, S. Isomorphism, diffusion and decoupling. In: GREENWOOD, R.; SUDDABY, R.; OLIVER, C.; SAHLIN-ANDERSON, K. (Eds.). Handbook of Organizational Institutionalism. New York: Sage, 2008. p. 78-98.

BRIERS, M.; CHUA, W. F. The role of actor-networks and boundary objects in management accounting change: a field study of an implementation of activity-based costing. Accounting, Organizations and Society, v. 26, n. 3, p. 237-269, 2001.

BURKERT, M.; LUEG, R. Differences in the sophistication of value-based management: the role of top executives. Management Accounting Research, v. 24, n. 1, p. 3-22, 2013.

CARDINAELS, E.; VAN VEEN-DIRKS, P. M. G. Financial versus non-financial information: the impact of information organization and presentation in a Balanced Scorecard. Accounting, Organizations and Society, v. 35, n. 6, p. 565-578, 2010.

CHENG, M. M.; HUMPHREYS, K. A. The differential improvement effects of the strategy map and scorecard perspectives on managers' strategic judgments. Accounting Review, v. 87, n. 3, p. 899-924, 2012.

COOPER, D. J.; EZZAMEL, M.; QU, S. Q. Popularizing a management accounting idea: the case of the Balanced Scorecard. Contemporary Accounting Research, v. 24, n. 2, p. 9911025, 2017.

CRABTREE, A. D.; DEBUSK, G. K. The effects of adopting the Balanced Scorecard on shareholder returns. Advances in Accounting, v. 24, n. 1, p. 8-15, 2008.

CRUZ, I.; MAJOR, M.; SCAPENS, R. W. Institutionalization and practice variation in the management control of a global/local setting. Accounting, Auditing \& Accountability Journal, v. 22, n. 1, p. 91-117, 2009.

CUNLIFFE, A. L. A very short, fairly interesting and reasonably cheap book about management. London: Sarge, 2009.

DAMAYANTHI, S; GOONERATNE, T. Institutional logics perspective in management control research: A review of extant literature and directions for future research. Journal of Accounting \& Organizational Change, v. 13, n. 4, p. 520-547, 2017.

DECHOW, N. The balanced scorecard: subjects, concept and objects - a commentary. Journal of Accounting \& Organizational Change, v. 8, n. 4, p. 511-527, 2012.

EZZAMEL, M.; ROBSON, K.; STAPLETON, P. The logics of budgeting: theorization and practice variation in the educational field. Accounting, Organizations and Society, v. 37, n. 5, p. 281-303, 2012.

FISS, P. C.; KENNEDY, M. T.; DAVIS, G. F. How golden parachutes unfolded: diffusion and variation of a controversial practice. Organization Science, v. 23, n. 4, p. 1077-1099, 2012.

FISS, P. C.; ZAJAC, E. J. The symbolic management of strategic change: sense giving via framing and decoupling. Academy of Management Journal, v. 49, n. 6, p. 1173-1193, 2006. 
GONDO, M. B.; AMIS, J. M. Variations in practice adoption: the roles of conscious reflection and discourse. Academy of Management Review, v. 38, n. 2, p. 229-247, 2013.

GUERREIRO, M. S.; RODRIGUES, L. L.; CRAIG, R. Voluntary adoption of International Financial Reporting Standards by large unlisted companies in Portugal - Institutional logics and strategic responses. Accounting, Organizations and Society, v. 37, n. 7, p. 482-499, 2012.

HOPPER, T; MAJOR, M. Extending institutional analysis through theoretical triangulation: regulation and activity-based costing in Portuguese telecommunications. European Accounting Review, v. 16, n. 1, p. 59-97, 2007.

HOQUE, Z. 20 years of studies on the balanced scorecard: trends, accomplishments, gaps and opportunities for future research. The British Accounting Review, v. 46, n. 1, p. 33-59, 2014.

HYVÖNEN, T.; JÄRVINEN, J.; PELLINEN, J.; RAHKO, T. Institutional logics, ICT and stability of management accounting. European Accounting Review, v. 18, n. 2, p. 241-275, 2009.

JAZAYERI, M.; SCAPENS, R. W. The business values scorecard within BAE systems: the evolution of a performance measurement system. The British Accounting Review, v. 40, n. 1, p. 48-70, 2008.

JOHANSON, U.; SKOOG, M.; BACKLUND, A.; ALMQVIST, R. Balancing dilemmas of the balanced scorecard. Accounting, Auditing \& Accountability Journal, v. 19, n. 6, p. 842-857, 2006.

JUSTESEN, L.; MOURITSEN, J. Effects of actor-network theory in accounting research. Accounting, Auditing \& Accountability Journal, v. 24, n. 2, p. 161-193, 2011.

The balanced scorecard: comments on balanced scorecard commentaries. Journal of Accounting \& Organizational Change, v. 8, n. 4, p. 539-545, 2012.

KAPLAN, R. S.; NORTON, D. P. Alignment: using the balanced scorecard to create corporate synergies. Boston, Mass.: Harvard Business School Press, 2006.

Conceptual foundations of the balanced scorecard. Handbooks of management accounting research, v. 3, p. 1253-1269, 2009.

Strategy maps: converting intangible assets into tangible outcomes. Boston, MA: Harvard Business School Press, 2004.

The balanced scorecard: measures that drive performance. Harvard Business Review, v. 70, n. 1, p. 7191, 1992.

The balanced scorecard: translating strategy into action. Boston, Mass.: Harvard Business School Press, 1996.

The execution premium: linking strategy to operations for competitive advantage.

Boston, MA: Harvard Business School Press, 2008. 
The strategy-focused organization: how balanced scorecard companies thrive in the new business environment. Boston, Mass.: Harvard Business School Press, 2001.

KENNEDY, M.; FISS, P. Institutionalization, framing, and diffusion: the logic of TQM adoption and implementation decisions among U.S. Hospitals. Academy of Management Journal, v. 52, n. 5, p. 897-918, 2009.

LANDER, M. W.; KOENE, B. A. S.; LINSSEN, S. N. Committed to professionalism: organizational responses of mid-tier accounting firms to conflicting institutional logics. Accounting, Organizations and Society, v. 38, n. 2, p. 130-148, 2013.

LAPSLEY, I; WRIGHT, E. The diffusion of management accounting innovations in the public sector: a research agenda. Management Accounting Research, v. 15, n. 3, p. 355374, 2004.

LATOUR, B. Science in action. Cambridge, MA: Harvard University Press, 1987.

LEE, C.-L.; YANG, H.-J. Organization structure, competition and performance measurement systems and their joint effects on performance. Management Accounting Research, v. 22, n. 2, p. 84-104, 2011.

LOUNSBURY, M. A tale of two cities: competing logics and practice variation in the professionalizing of mutual funds. The Academy of Management Journal, v. 50, n. 2, p. 289-307, 2007.

Institutional rationality and practice variation: new directions in the institutional analysis of practice. Accounting, Organizations and Society, v. 33, n. 4-5, p. 349-361, 2008.

LOUNSBURY, M.; CRUMLEY, E. T. New practice creation: an institutional perspective on innovation. Organization Studies, v. 28, n. 7, p. 993-1012, 2007.

LOUNSBURY, M.; VENTRESCA, M. The new structuralism in organizational theory. Organization, v. 10, n. 3, p. 457-480, 2003.

MALMI, T. Balanced scorecards in Finnish companies: a research note. Management Accounting Research, v. 12, n. 2, p. 207-220, 2001.

MALMI, T. Activity-based costing diffusion across organizations: an exploratory empirical analysis of Finnish firms. Accounting, organizations and society, v. 24, n. 8, p. 649-672, 1999.

MODELL, S. Bundling management control innovations: a field study of organisational experimenting with total quality management and the balanced scorecard. Accounting, Auditing \& Accountability Journal, v. 22, n. 1, p. 59-90, 2009.

The politics of the balanced scorecard. Journal of Accounting \& Organizational Change, v. 8, n. 4, p. 475-489, 2012.

NADLER, D. A.; TUSHMAN, M. L. A model for diagnosing organizational behavior. Organizational Dynamics, v. 9, n. 2, p. 35-51, 1980. 
NORREKLIT, H. The balance on the balanced scorecard a critical analysis of some of its assumptions. Management Accounting Research, v. 11, n. 1, p. 65-88, 2000.

NORREKLIT, H.; MITCHELL, F. The balanced scorecard. In: Hopper, T.; Scapens, R. W.; Northcott, D. (Eds.). Issues in management accounting, 3rd ed. Harlow: Financial Times Prentice Hall, 2007. p. xxii, 458.

NØRREKLIT, H.; NØRREKLIT, L.; MELANDER, P. US 'fair contract' based performance management models in a Danish environment. Financial Accountability \& Management, v. 22, n. 3, p. 213-233, 2006.

NØRREKLIT, H.; NØRREKLIT, L.; MITCHELL, F.; BJØRNENAK, T. The rise of the balanced scorecard! Relevance regained? Journal of Accounting \& Organizational Change, v. 8, n. 4, p. 490-510, 2012.

OLIVER, C. The antecedents of deinstitutionalization. Organizational Studies, v. 13, n. 4, p. 563-588, 1992.

PACHE, A. C.; SANTOS, F. When worlds collide: the internal dynamics of organizational responses to conflicting institutional demands. Academy of Management Review, v. 35, n. 3, p. 455-476, 2010.

PRESTON, A. M.; COOPER, D. J.; COOMBS, R. W. Fabricating budgets: a study of the production of management budgeting in the national health service. Accounting,

Organizations and Society, v. 17, n. 6, p. 561-593, 1992.

QU, S.Q.; COOPER, D. J.; EZZAMEL, M. Creating and popularising a global management accounting idea: The case of the Balanced Scorecard. Research Executive Summary Series, v. 6, n. 13, p 1-5, 2010.

RIGBY, D.; BILODEAU, B. Management tools and trends: 2011. Boston, MA: Bain \& Co, 2011.

ROGERS, E. M. Diffusion of innovations. 4th ed. New York: The Free Press, 1995.

SEO, M.-G.; CREED, W. E. D. Institutional contradictions, praxis, and institutional change: a dialectical perspective [institutional theory]. Academy of Management Review, v. 27, n. 2, p. 222-247, 2002.

SMETS, M. et al. Reinsurance trading in Lloyd's of London: Balancing conflicting-yetcomplementary logics in practice. Academy of Management Journal, v. 58, n. 3, p. 932 970, 2015.

SPECKBACHER, G.; BISCHOF, J.; PFEIFFER, T. A descriptive analysis on the implementation of balanced scorecards in German-speaking countries. Management Accounting Research, v. 14, n. 4, p. 361-388, 2003.

STURDY, A. The adoption of management ideas and practices: theoretical perspectives and possibilities. Management Learning, v. 35, 155-179, 2004.

SUDDABY, R. Challenges for institutional theory. Journal of Management Inquiry, v. 19, n. 1, p. 14-20, 2010. 
SUDDABY, R.; ELSBACH, K. D.; GREENWOOD, R.; MEYER, J. W.; ZILBER, T. B. Organizations and their institutional environments - bringing meaning, values, and culture back in: introduction to the special research forum. Academy of Management Journal, v. 53, n. 6, p. 1234-1240, 2010.

SUNDIN, H.; GRANLUND, M.; BROWN, D. A. Balancing multiple competing objectives with a balanced scorecard. European Accounting Review, v. 19, n. 2, p. 203-246, 2010.

TAYLER, W. B. The balanced scorecard as a strategy-evaluation tool: the effects of implementation involvement and a causal-chain focus. The Accounting Review, v. 85, n. 3, p. 1095-1117, 2010.

TAYLOR, M. The dynamics of US managerialism and American corporations. In: SLATER, D.; TAYLOR, F. J. (Eds.). Consensus and coercion in the projection of American power. Oxford: Blackwell, 1999. p. 51-66.

THORNTON, P. H. The rise of the corporation in a craft industry: conflict and conformity in institutional logics. Academy of Management Journal, v. 45, n. 1, p. 81-101, 2002.

THORNTON, P. H.; JONES, C.; KURY, K. Institutional logics and institutional change in organizations: transformation in accounting, architecture, and publishing. In: THORNTON, P. H.; JONES, C. (Eds.). Transformation in cultural industries. Research in the Sociology of Organizations, v. 23, p. 125-170, 2005.

THORNTON, P. H.; OCASIO, W. Institutional logics. In: GREENWOOD, R.; OLIVER, C.; SUDDABY, R.; SAHLIN, K. (Eds.). The Sage Handbook of Organizational

Institutionalism. Thousand Oaks, CA: Sage, 2008. p. 99-129.

THORNTON, P. H.; OCASIO, W.; LOUNSBURY, M. The institutional logics perspective: a new approach to culture, structure, and process. Oxford: Oxford University Press, 2012.

TOLBERT, P. S.; ZUCKER, L. G. Institutional sources of change in the formal structure of organizations: the diffusion of civil service reform, 1880-1935. Administrative Science Quarterly, v. 28, n. 1, p. 22-39, 1983.

WAGNER, E. L.; MOLL, J.; NEWELL, S. Accounting logics, reconfiguration of ERP systems and the emergence of new accounting practices: a socio-material perspective. Management Accounting Research, v. 22, n. 3, p. 181-197, 2011.

WONG-ON-WING, B.; GUO, L.; LI, W.; YANG, D. Reducing conflict in balanced scorecard evaluations. Accounting, Organizations and Society, v. 32, n. 4-5, p. 363-377, 2007.

WONG, J.; CHIANG, R. H. L.; MCLEOD, A. A strategic management support architecture: integration of the balanced scorecard and enterprise resource planning. International Journal of Business Information Systems, v. 4, n. 5, p. 581-595, 2009.

ZEFF, S. A. The contribution of the Harvard Business School to management control, 19081980. Journal of Management Accounting Research, v. 20, n. especial, p. 175-208, 2008. 